Antonius Baehr-Oliva

Venus-Dichtungen im deutschen Barock (1624-1700) 


\section{Frühe Neuzeit}

Studien und Dokumente zur deutschen Literatur und Kultur im europäischen Kontext

Herausgegeben von

Achim Aurnhammer, Wilhelm Kühlmann,

Jan-Dirk Müller, Martin Mulsow und Friedrich Vollhardt

\section{Band 236}


Antonius Baehr-Oliva

Venus-Dichtungen

im deutschen Barock

(1624-1700)

Mythenkorrekturen und Transformationen

DE GRUYTER 
Gedruckt mit freundlicher Unterstützung der Geschwister Boehringer Ingelheim Stiftung für Geisteswissenschaften in Ingelheim am Rhein

ISBN 978-3-11-067977-9

e-ISBN (PDF) 978-3-11-068420-9

e-ISBN (EPUB) 978-3-11-068426-1

ISSN 0934-5531

\section{Library of Congress Control Number: 2020930225}

\section{Bibliografische Information der Deutschen Nationalbibliothek}

Die Deutsche Nationalbibliothek verzeichnet diese Publikation in der Deutschen Nationalbibliografie; detaillierte bibliografische Daten sind im Internet über http://dnb.dnb.de abrufbar.

(c) 2020 Walter de Gruyter GmbH, Berlin/Boston

Satz: Integra Software Services Pvt. Ltd.

Druck und Bindung: $\mathrm{CPI}$ books $\mathrm{GmbH}$, Leck

www.degruyter.com 